situation and evaluated their own performance. Job identification and responsibility are essential for both senior and junior staff morale and functioning. Organization (information flow, orderly work, and task allocation) is critical in coping with chaotic situations like that generated by the tsunami. Team cohesiveness makes them better able to withstand prolonged exposure to the stresses generated by severe disaster. Positive thinking and orientation towards the future gives people strength and motivation to keep working. Those who had volunteered for the disaster team were found to be more supportive and immunizing than those who had been asked to work with the team. Technical problems (such as the language barrier vis-a-vis the tourists were a cause of stress and the elimination of such problems (through the position of translators in healthcare facilities) alleviated that stress.

Keywords: disaster medical response; evaluation; healthcare; interviews; Israel; leadership; stress factors; Thailand; tsunami Prebosp Disast Med 2005;20(3):s119-s120

\section{Medical Repatriation of Swedish Citizens Injured in the 26 December 2004 Tsunami}

\section{J. Holst; A. Ljungquist}

Department of Emergency and Disaster Planning, National Board of Health and Welfare, Sweden

Swedish tourists are prominent in Thailand, especially in the Phuket region. The tsunami, caused by the earthquake near the northwest coast of Indonesia, impacted Khau Lac, one of the most popular areas used by Swedes. After 96 hours, 70-80 patients with relatives in the hospitals of Phuket and in the surrounding rural area remained in Thailand. The Swedish government arranged the evacuation of these hospitalized causalities. The process used will be presented.

A Medevac team of 18 persons left Sweden 84 hours after the tsunami had occurred. After localization of the patients, each was evaluated with respect for the risks associated with a prolonged, airborne evacuation. The repatriation was performed during the following 72 hours using various types of aircraft. One bottleneck was the limited capacity of available intensive care beds. The experiences obtained from the operation supports the need for: (1) coordinated structures in the healthcare system; (2) education; (3) training of medical teams to be prepared to take part in complex international operations; and (4) systems for performing needs assessments to guide the allocation of resources.

Keywords: coordination; evacuation; intensive care; needs assessment; repatriation; Sweden; Thailand; tsunami

Prehosp Disast Med 2005;20(3); 120

\section{Central System for Psychosocial Support of Czech Victims Affected by the Tsunami in Southeast Asia S. Vymetal \\ Ministry of Interior of the Czech Republic, Czech Republic}

Introduction: The Czech Republic has a population of 10 million. More than $300 \mathrm{Czech}$ citizens were reported as missing on the day following the tsunami in Southeast
Asia. After three weeks, 11 seriously injured patients and one dead person had been found. Also, hundreds of Czechs were traumatized mentally by this event. The Ministry of Interior (MIO) coordinated the psychological and psychosocial support to the victims in the Czech Republic.

Methods: Methods used included case study and both qualitative and quantitative data collection and processing. Results: Three hundred patients, of a total 1,400 tourists monitored by the team in airports in Prague, were Czech.

1. Psychological belp line: The MIO found that $80-90 \%$ of emergency calls for help during the first three weeks were related to the tsunami. Fifty-sixty percent of the total calls were related to acute and very serious injuries and/or illnesses; $10 \%$ of the critical calls required interventions, and $20 \%$ of the calls required professional or humanitarian support;

2. Team for psychological assistance: The tasks and responsibilities of the team were: (1) assistance at the airports; (2) crisis intervention; (3) psychological "first aid"; (4) assistance in the collection of DNA material from relatives; and (5) supporting surviving relatives;

3. Making and distributing printed and electronic material: The MIO provided leaflets with instructions, handbooks, and an address list of psychosocial service available in the Czech Republic. Not only was the material provided to Czech tourists, but also for their relatives, other professionals, and employees of the Czech airline. It was produced in English for foreigners;

4. Regional network of psychosocial support in the Czech Republic,

5. Helping concerned people: There are 150 professional contacts, including psychologists, doctors, priests, social workers, police officers, and firemen. They are certified in Critical Incident Stress Management;

6. Collaboration among departments: Cooperation included: the Ministry of Interior, Ministry of Health, Ministry of Foreign Affairs, and Ministry of Defense. Also included were Czech embassies in the affected areas of Asia, Czech Airlines, Prague airports, and travel agencies; and

7. Process of analyzing and making prognoses: the consequences for the affected victims, the effectiveness and evaluation of the helpfulness of this system during the entire process have been analyzed.

Conclusion: Approximately, 1,500 people were evaluated psychologically via telephone contact and at the airports, and were given instructions and handbooks during the first three weeks after the event. Of these, approximately 450 were Czech citizens. Television, newspapers, and websites informed hundreds of people about the availability of psychological help. The detailed research continues.

Keywords: collaboration; consequences; Czech Republic; injuries; patients; process; psychological; psychosocial; stress; support; tsunami

Prebosp Disast Med 2005;20(3):s120 